\title{
ALGUNAS NOTAS EN TORNO A LA PRESENTACIÓN PARLAMENTARIA DEL INFORME ANUAL POR LOS DEFENSORES DEL PUEBLO
}

\author{
POR \\ ALBERTO ANGUITA SUSI \\ Doctor en Derecho \\ Prof. Asociado de Derecho Constitucional \\ Universidad de Jaén
}

\section{INTRODUCCIÓN}

Para comprender la elección del tema que se aborda en este trabajo es necesario tener en cuenta, como punto de partida, que cuando hablamos de Ombudsman nos estamos refiriendo a una Institución elegida por el Parlamento y que, en nombre de éste, supervisa la actuación de la Administración pública al objeto de verificar la existencia de vulneraciones en los derechos y libertades fundamentales de los particulares. En efecto, pese a la imparable evolución que ha experimentado el Ombudsman en aquellos países que lo han importado a sus respectivos ordenamientos jurídicos ${ }^{1}$, aquél conserva, no obstante, una

1 Al respecto, consúltese a Pellón Rivero, R., "La metamorfosis del Ombudsman", en Rev. Documentación Administrativa, n. ${ }^{\circ} 161$, 1974, p. 25; OeHLING RuIz, H., "El Defensor del Pueblo: algunos problemas de su adaptación orgánico-funcional», en Rev. de Estudios Políticos, n. ${ }^{\circ} 72,1991$, pp. 89 a 128; y CARballo Armas, P., "Episodios de la difusión del Ombudsman en el constitucionalismo comparado: una 
serie de rasgos originales que definen su idiosincrasia; entre ellos destaca la elección parlamentaria y la necesidad de trasladar al Parlamento el resultado de la actividad desplegada.

La correcta satisfacción del trámite de la presentación de los Informes no sólo va a permitir que el Defensor del Pueblo cumpla la misión que tiene encomendada, sino también que el Parlamento cuente con el material necesario para adoptar las medidas que ayuden a paliar los problemas sociales denunciados en los Informes. El Parlamento, por tanto, debe recibir, en todo caso y momento, cumplida cuenta de la actuación llevada a cabo por su comisionado. Cuestión distinta es que la presentación de los Informes no pueda ser entendida actualmente bajo las clásicas coordinadas que configuraban al Ombudsman como una longa manus del Parlamento. Antes al contrario, debe considerarse que dicha presentación supone un acto mediante el cual el Defensor del Pueblo comunica formalmente al Parlamento el resultado de sus actuaciones.

\section{LA CONFIGURACIÓN DEL DEFENSOR DEL PUEBLO COMO ÓRGANO COMISIONADO Y AUXILIAR DEL PARLAMENTO}

La obligación del Defensor del Pueblo (DP) de dar cuenta al Parlamento encuentra su justificación en el hecho de que el primero funciona como un comisionado del segundo: la Constitución, los Estatutos y la normativa de desarrollo adscriben al DP respectivo dentro de la órbita parlamentaria, apartándolo de la influencia del Poder Ejecutivo². Ahora bien, la configuración como un órgano comisionado del Parlamento no significa que los Defensores del Pueblo carezcan de autonomía desde un punto de vista funcional, en la medida en que no están sujetos a mandato imperativo alguno y no pueden recibir instrucciones de ninguna autoridad ${ }^{3}$. Si a esto unimos la posibilidad, prevista en la

aproximación analítica a los modelos de Italia, Portugal y la Unión Europea», en Anuario Parlamento y Constitución, n. ${ }^{\circ} 3,1999$, pp. 153 a 181.

2 Lozano Miralles matiza, sin embargo, que esta "adscripción no implica diferencias substanciales, ya que el Parlamento y, en consecuencia, el órgano de control están controlados por el partido o coaliciones políticas que apoyan al Gobierno". (Configuración e independencia de los órganos de control externo: un análisis comparado, Civitas-Cámara de Cuentas, Madrid, 1996, p. 62). En la misma línea, PéREZUgena y Coromina, M. ${ }^{a}$, Defensor del Pueblo y Cortes Generales, Congreso de los Diputados, Madrid, 1996, p. 176.

${ }^{3}$ El art. 1.3 de la Ley del Ararteko (Defensor del Pueblo) del País Vasco dispone: «Es una Institución pública prevista directamente por el Estatuto de Autonomía, independiente de las Administraciones Públicas, que sólo recibe instrucciones del 
Constitución y en algunas leyes reguladoras, de que los Defensores del Pueblo insten la interposición de un recurso de inconstitucionalidad contra las leyes elaboradas por el Parlamento al que deben rendir cuentas, cabría afirmar que la relación entre ambos no es la que une a un mandante con un mandatario, sino la de dos órganos con facultades de control que mantienen un equilibrio mutuo.

Por otro lado, hay que señalar que la figura del DP no sólo funciona como un comisionado sino también como un órgano auxiliar del Parlamento. En este sentido, es posible distinguir entre órganos constitucionales o estatutarios, situados en una posición de paridad con el resto de órganos estatales y autonómicos que participan en la dirección política y que disponen de autonomía orgánica, funcional, reglamentaria y presupuestaria; y órganos de relevancia constitucional o estatutaria, a los que corresponde cumplir funciones auxiliares de garantía, control y consulta frente a los órganos constitucionales y estatutarios propiamente dichos ${ }^{4}$.

Esta distinción, según Blanco Herranz, «nos muestra un perfil del "órgano auxiliar" ciertamente distante de la subordinación o dependencia en su relación con el órgano primario y más orientada a resaltar su función de ayuda técnica o colaboración con el órgano primario en atención a su concreta cualificación, en aquellas actividades o funciones que se le asignen ${ }^{5}$. Los Defensores del Pueblo, por tanto, contribuyen

Parlamento, en la forma que éste determine (...)". En opinión de LóPEZ BASAGUREN y Maestro Buelga, este precepto habilita al Parlamento vasco para dictar normas que reglamenten la actuación del Ararteko pero no órdenes concretas y pormenorizadas. (El Ararteko, Instituto Vasco de Administración Pública, Oñati, 1993, pp. 200 y 201). Asimismo, LA PERgola opina que las Cámaras Legislativas no son destinatarias pasivas de los informes del Defensor del Pueblo sino que deben ser parte activa dirigiendo la conducta de éste; eso sí, mediante directrices generales que posibiliten un margen de actuación y autonomía funcional («Introduzione» a la obra Ricerca sul Commissario Parlamentare. Ordinamenti stranieri e progetti italiani, Quaderni di Studi e Legislazione, Camera dei Diputati, Roma, 1971, p. 13).

4 Vid. Merino Merchán, J.F., Instituciones del Derecho Constitucional español, Centro de Estudios Superiores Sociales y Jurídicos Ramón Areces, Madrid, 1994, pp. 707 y 708; y Aguilar Fernández-Hontoria, J., "A propósito del Defensor del Pueblo: rasgos definidores de la posición jurídica de los órganos auxiliares", en AAVV, Las Cortes Generales (Vol. I), Ministerio de Economía y Hacienda-Instituto de Estudios Fiscales, Madrid, 1987, pp. 345 y 346.

5 "Los órganos dependientes del Parlamento Vasco. El Tribunal Vasco de Cuentas Públicas y el Ararteko", en AAVV., Seminario sobre Derecho parlamentario, Parlamento Vasco, Vitoria, 1990, p. 328. También puede verse a VALERA SUANZES-CARPEGNA, J., "La naturaleza jurídica del Defensor del Pueblo", en Rev. Española de Derecho Constitucional, n. ${ }^{\circ} 8,1983$, p. 64; y AguILAR FeRnándeZ-HontoriA, J., "A propó- 
técnicamente a que el Parlamento pueda llevar a cabo las funciones que le vienen encomendadas, entre las cuales ocupan un lugar destacado las funciones legislativa y de control. Por lo que respecta a la primera función, el DP está capacitado para sugerir tanto la modificación como la elaboración de normas. En cuanto a la segunda, cabe afirmar que nos encontramos ante un "órgano de control parlamentario indirecto", tal y como ha señalado mayoritariamente la doctrina ${ }^{6}$.

\section{LA PRESENTACIÓN PARLAMENTARIA DE LOS INFORMES}

La "rendición de cuentas" a la que está obligada todo DP se materializa a través de la presentación parlamentaria de los Informes que, además de la culminación de la actuación desplegada, supone trasladar al Parlamento los problemas detectados con el fin de que éste adopte las medidas oportunas. En todo caso, dada la necesidad de que el Parlamento reciba "cumplida cuenta" de la actuación desarrollada por su comisionado, la presentación de los Informes debe llevarse a efecto siguiendo una serie de formalidades. No obstante, antes de adentrarnos en esta materia convendría precisar que la "auténtica dación de cuentas" tiene lugar cuando el DP presenta el Informe anual ante el Pleno del Parlamento, supuesto al que vamos a circunscribir nuestro análisis, y no ante la Comisión encargada de articular las relaciones parlamentarias con el DP correspondiente.

\subsection{Tiempo}

El acto de presentación del Informe anual adquiere pleno sentido sólo cuando el Parlamento recibe una información actualizada de su comisionado; por ello, resulta paradójico que la mayoría de leyes vigentes en la materia no hayan previsto plazo alguno para presentar los Infor-

sito del Defensor del Pueblo: rasgos definidores de la posición jurídica de los órganos auxiliares", op. cit. p. 377 y ss.

6 Vid. Santaolalla LóPEZ, F., "Las funciones parlamentarias en relación con los órganos auxiliares del Parlamento", en AAVV (Ed. Garrorena Morales, A.)., El Parlamento y sus transformaciones actuales, Tecnos, Madrid, 1990, pp. 370 y 371; FERNÁNDEZ SARASOLA, I., "El control parlamentario y su regulación en el ordenamiento español", en Rev. española de Derecho Constitucional, n. ${ }^{\circ} 60,2000$, pp. 102 a 106; y BLANCO VALDÉs, R., "Las peculiaridades del control del Gobierno en las Comunidades Autónomas", en AAVV (Coords. Elvira Perales, A. y González Ayala, M. a D.)., Nuevos retos del control parlamentario: Comunidades Autónomas y Unión Europea, Tirant lo Blanch, Valencia, 2002, pp. 21 y 25. 
mes anuales ante el Parlamento respectivo ${ }^{7}$. Si bien, en principio, podría resultar contraproducente someter el debate parlamentario a reglas de procedimiento rígidas, debido a que en la mayoría de los casos la práctica discurre por derroteros alejados a los que marca la norma parlamentaria, no cabe desconocer que la ausencia de plazo puede provocar que el contenido de los Informes carezca de actualidad.

Aunque este contratiempo suele deberse a una serie de factores propios de la "práctica parlamentaria" -debate previo del Informe en Comisión, redacción del texto del Informe por los Defensores del Pueblo y consulta de su contenido por los parlamentarios antes de ser debatidos-, hay que tener en cuenta que la presentación extemporánea de los Informes constituye un claro incumplimiento del acto de "dación de cuentas", pues no basta con que el DP cumpla dicho cometido de cualquier forma sino que se trata de "dar cumplida cuenta" de la labor realizada, lo que sólo podrá satisfacerse si el Informe anual es presentado con premura ante el Parlamento.

La fijación de una fecha para la presentación de los Informes supondría, además, una garantía ante el Parlamento, dado que pueden existir intereses políticos para que la presentación de dichos Informes se retrase o se adelante ${ }^{8}$. Ante la ausencia de previsión legal al respecto, en la práctica debería procurarse, de una parte, que el DP elaborara puntualmente sus Informes y, de otra, que el Parlamento propiciara, en la medida de lo posible, la inmediata presentación de los mismos ante el Pleno.

\subsection{Forma}

La preparación de los Informes antes de ser debatidos en la Cámara se concreta en la redacción material y en la estructuración de los

7 Las excepciones vienen dadas por los arts. 30.1 de la Ley del Sindic de Greuges catalán y 35.1 de la Ley del Justicia aragonés, en los que se establece que la presentación del Informe anual deberá producirse en el plazo de treinta días a partir del inicio del segundo período ordinario de sesiones. El art. 46 de la Ley canaria, por su parte, prevé que el Informe anual se presentará antes del 30 de mayo del año siguiente.

${ }^{8}$ En el Parlamento de Andalucía el representante de IU, Sr. Granados Navas, solicitó el cese del titular basándose en que el Informe de 1990 fue presentado extemporáneamente por el Defensor del Pueblo Andaluz con el supuesto fin de favorecer al partido de Gobierno ante la inminente celebración de elecciones autonómicas. (Diario de Sesiones del Parlamento de Andalucía de 12 de febrero de 1991, pp. 1109 y 1110). 
contenidos, elementos de los que depende, en gran medida, la calidad final del documento elaborado.

En cuanto a la redacción material se refiere hay que señalar, como advierte Ordoqui Urdaci, que el "prestigio y la autoridad de un órgano de control está directamente relacionado con el rigor y la calidad de los Informes que realiza ${ }^{9}$. Al respecto, puede decirse que, en líneas generales, los informes elaborados por los Defensores del Pueblo suelen pecar de un excesivo formalismo jurídico que, en ocasiones, convierte su lectura en una tarea sólo apta para técnicos en Derecho. En favor de esta práctica podría esgrimirse que la divulgación y explicación de los argumentos empleados en la investigación sirve para dar a conocer públicamente cuál es la posición de cada DP sobre un asunto. Sin embargo, si lo que se pretende es que el contenido de los Informes no sólo sea conocido por el Parlamento sino también por el conjunto de la sociedad, no parece que deban incluirse en ellos constantes referencias a la normativa y jurisprudencia aplicable, a la opinión de la doctrina y a los órganos de la Administración que intervienen en la resolución de un asunto; sin olvidar el exceso de información descriptiva utilizada para ubicar la problemática objeto de las quejas.

Por lo que a la estructura respecta, es indudable que una sistemática adecuada facilita la comprensión y consulta de los Informes tanto por el Parlamento como por la sociedad ${ }^{10}$; además de constituir un indicador de primer orden para dar a conocer cuáles son las prioridades e inquietudes del DP, su funcionamiento, las materias sobre las que interviene y el método de trabajo seguido, entre otros aspectos.

Pese a lo anterior, la estructura de los Informes va a verse condicionada por las competencias que le vienen asignadas a cada DP y por el contenido de cada Informe. En relación a este aspecto convendría distinguir entre las leyes que introducen una "cláusula abierta", en

9 «Importancia de los órganos autonómicos de control externo y claves para su buen funcionamiento", en AAVV, Los órganos de control externo y el sector público, Cámara de Cuentas de Andalucía, Sevilla, 1992, pp. 18 a 22.

10 En la presentación del Informe anual correspondiente a 1989, el Defensor del Pueblo Andaluz señalaba al respecto que estamos ante «un documento totalmente nuevo, nuevo en cuanto distinto, y mejorado en relación a los Informes de años anteriores. En tal sentido, evidentemente ha representado un serio esfuerzo por parte de todo el equipo que intervino en su redacción, de tal forma que el resultado final ha pretendido ser más completo, ordenado, racional y clarificador en su conjunto y en los aspectos concretos de las distintas cuestiones y actuaciones llevadas a cabo". (Diario de Sesiones del Parlamento de Andalucía de 12 de febrero de 1991, p. 1100). 
virtud de la cual el DP gozará de libertad para incluir en los Informes aquellos contenidos que estime oportunos, tal y como sucede con los arts. 32.2 de la Ley del Ararteko vasco y 47.1 de la Ley del Diputado del Común canario; y aquellas normas que prevén una "cláusula de mínimos" aplicable al contenido de los Informes anuales ${ }^{11}$. Pese a esta distinción, la mayoría de la doctrina considera que la ampliación del contenido de los Informes anuales es algo permitido implícitamente por las leyes vigentes, en la medida en que los aspectos formales no deben dejar al margen aquellos contenidos que pueden resultar necesarios para conocer el estado en el que se encuentra la Administración pública ${ }^{12}$. De hecho, el contenido de los Informes ha ido ganando en complejidad en la práctica debido a tres factores: la progresiva consolidación institucional de la figura del DP, el conocimiento por los ciudadanos de sus competencias y la ampliación del ámbito de supervisión provocado por el desarrollo del Estado autonómico.

Teniendo en cuenta todo lo anterior, proponemos como «estructura ideal” de los Informes anuales la siguiente:

- Tutela de derechos. Este apartado estaría dedicado a analizar la situación general en la que se encuentran los derechos fundamentales; las actuaciones emprendidas de oficio (quejas de oficio e Informes especiales) con el fin de proteger los derechos de los colectivos más desfavorecidos; y las actividades de divulgación realizadas para la promoción y defensa de los derechos fundamentales.

- Análisis de las quejas recibidas y tramitadas en cada área. Las quejas podrían ser estructuradas atendiendo, bien a la división en áreas seguida por la propia Administración, bien a las áreas en las que se estructura la Oficina de cada comisionado. Asimismo, debería hacerse mención a los expedientes de queja aún pendientes de tramitación.

- Quejas rechazadas y sus causas. Aquí se trataría de exponer detalladamente los motivos que han llevado al DP a rechazar algu-

11 Las distintas leyes reguladoras de los Defensores del Pueblo determinan que el Informe anual dará cuenta del número y tipo de quejas presentadas, de aquéllas que hubiesen sido rechazadas y sus causas, de las investigadas y del resultado de las mismas, así como de las sugerencias o recomendaciones admitidas por la Administración autonómica. Asimismo añaden que los Informes deberán contener la liquidación del presupuesto de la Institución.

${ }_{12}$ Por todos, Pérez-Ugena y Coromina, M. a, Defensor del Pueblo y Cortes Generales, op. cit. p. 271. 
nas quejas, con el doble objetivo de evitar que su actuación pueda ser tachada de arbitraria y de informar al ciudadano de cuáles son sus verdaderas competencias.

- Grado de colaboración mostrado por la Administración. En este apartado cabría incluir no sólo las incidencias negativas surgidas durante el transcurso de la investigación, como los casos de no colaboración, sino también la referencia aquellos órganos administrativos que se hayan caracterizado por su reiterada colaboración con la Institución.

- Grado de cumplimiento de las recomendaciones formuladas. Los Informes deben dar cuenta en este punto de las distintas técnicas de seguimiento utilizadas en la práctica por cada DP con el fin de verificar si la Administración ejecuta finalmente las medidas a las que se comprometió. Sería conveniente, igualmente, hacer un seguimiento de las disposiciones normativas aprobadas y de los mecanismos de control parlamentarios activados a raíz de la presentación de los Informes.

- Relaciones institucionales. Este apartado debe informar de las comparecencias del DP ante el Parlamento, tanto para presentar los correspondientes Informes como para informar al mismo de cualquier asunto. Asimismo, habría que incluir las relaciones mantenidas con otros Comisionados - firma de convenios, actuaciones conjuntas, remisión de quejas- así como con otras instituciones -órganos oficiales, universidades, asociaciones, etc.-.

- Anexos. La parte final de los Informes estaría dedicada a los datos estadísticos más relevantes que resulten de la tramitación de las quejas y demás actuaciones emprendidas por el DP.

\subsection{Presentación}

Como dijimos anteriormente, la presentación del Informe anual supone para el DP la culminación de sus investigaciones, el perfeccionamiento de la rendición de cuentas ante el Parlamento y la propuesta de las medidas necesarias para paliar los problemas que aquejan a los particulares. La presentación del Informe anual constituye, por tanto, la suprema escenificación de la dación cuentas que todo comisionado debe rendir al Parlamento, si bien este acto no es consecuencia de una relación fiduciaria sino la expresión del deber del primero de informar al se- 
gundo de la actividad desarrollada ${ }^{13}$. Es más, la presentación del Informe anual "ya no puede entenderse como una "dación de cuentas" ante la Cámara, sino como el momento principal de la comunicación del trabajo de la Institución al Parlamento, resto de poderes públicos y sociedad ${ }^{14}$. La correcta satisfacción de este trámite exige tener en cuenta lo siguiente.

Desde un punto de vista procedimental, la mayoría de leyes autonómicas disponen que los Informes anuales tienen que ser evacuados, en primera instancia, ante la Comisión parlamentaria encargada de canalizar las relaciones entre el DP y el Parlamento y, en segunda, ante el Pleno. Sin perjuicio de que, como dijimos en su momento, la "rendición de cuentas" se satisfaga en esta sede, dado que el Pleno representa institucionalmente al Parlamento y es el lugar donde el debate parlamentario alcanza un mayor grado de publicidad, este doble trámite persigue, de un lado, que los Grupos parlamentarios verifiquen en Comisión que el Informe cumple los requisitos necesarios para ser presentado ante el Pleno y, de otro, que en el Pleno valoren políticamente y fijen sus posiciones. No obstante, la práctica parlamentaria ha demostrado que el debate en Comisión no siempre ha sido utilizado para concretar los aspectos técnicos de los Informes sino para valorar políticamente el contenido de los mismos. Asimismo, hay que señalar que la exigencia de presentar el Informe en Comisión y en Pleno ha dado lugar, en la mayoría de los casos, a que los términos del debate se reiteren en ambas sedes.

Desde una perspectiva material, las comparecencias parlamentarias de los Defensores del Pueblo se limitan, como regla general, a hacer una descripción general de la actividad desarrollada apoyada en cifras estadísticas y a exponer los principales problemas contenidos en las quejas recibidas en cada área. O lo que es lo mismo, en dichas comparecencias el titular presenta ante el Parlamento un resumen del Informe anual sintetizando una información que los Diputados conocen de antemano a través del Boletín Oficial del Parlamento, de Internet o

${ }^{13}$ El prof. J. J. RuIz-Rıco, precisa al respecto que «dado que el Defensor del Pueblo no está vinculado con el Parlamento por una relación de confianza política puede entenderse que el Defensor en su informe no da cuenta de "su" actuación sino de la actuación de otros (por ejemplo, la Administración autonómica) conocida a través de su actuación. Con lo que, si se nos permite usar la expresión vulgar, hay un desplazamiento respecto a quién puede "pedirle cuentas" al Parlamento». ("El Defensor del Pueblo Andaluz», en AAVV (Coords. Porras Nadales, A. y Ruiz-Rico, J. J.), El Estatuto de Andalucía. Estudio sistemático, Ariel, Barcelona, 1990, p. 204).

14 Díez Bueso, L., Los Defensores del Pueblo (Ombudsmen) de las Comunidades Autónomas, Temas del Senado, Madrid, 1999, p. 121. 
del propio texto del Informe que el DP entrega a los Grupos antes de su presentación y debate parlamentario ${ }^{15}$. Con el fin de evitar esta disfunción entendemos que la presentación del Informe debe servir para que el DP plantee las líneas principales de trabajo desarrolladas, las prioridades de actuación y las medidas que ayuden a mejorar la actuación de la Administración. Las "comparecencias-resumen», en consecuencia, deben dar paso a un estilo más directo a la hora de plantear los problemas y de inquirir al Parlamento a que adopte las medidas legislativas y políticas oportunas, de manera que se consolidara un modelo de «informe-debate» frente al «informe-descripción» ${ }^{16}$.

\section{CONCLUSIONES}

Como hemos tenido la oportunidad de comprobar en este trabajo, el "modelo clásico» de Ombudsman se caracteriza por su elección parlamentaria y porque éste debe rendir cuentas al órgano que lo nombró. Bajo este esquema puede afirmarse que tanto la elección como la rendición de cuentas constituyen los dos momentos en los que se manifiesta la "dependencia orgánica" del DP respecto al Parlamento.

Ahora bien, el hecho de que dicha "dependencia" no pueda ser entendida en términos de subordinación jerárquica explica que la presentación parlamentaria de los Informes sea el acto mediante el cual el DP traslada al Parlamento el resultado de sus actuaciones. Precisamente por ello, dicha presentación debe sujetarse a una serie de parámetros con el fin de lograr un doble objetivo: que el Parlamento pueda llevar a cabo una serie de medidas coherentes con los problemas que plantean los Informes, y que el DP pueda culminar con éxito el conjunto de actuaciones desplegadas en el ejercicio de sus funciones.

Puesto que la presentación de los Informes no supone una rendición de cuentas en sentido propio y sí un acto de comunicación formal del conjunto de actuaciones desarrolladas por el DP, resulta crucial que dicha presentación responda a la función que realmente debe cumplir y no a otros intereses subyacentes. La fijación, en consecuencia, de unos parámetros aplicables al acto de presentación de los Informes va a ser de gran utilidad para reforzar la eficacia, legitimación social e independencia del DP.

${ }^{15} \mathrm{El}$ art. 37 de la Ley del Justicia de Aragón establece que éste debe proporcionar a los Diputados el texto del Informe anual con al menos 15 días de antelación a su presentación parlamentaria.

${ }_{16}$ Mas I Solench, J. M., El Síndic de Greuges de Catalunya, Generalitat de Catalunya, Barcelona, 1995, p. 112. 
De todas formas, la imagen de independencia que proyecta la presentación parlamentaria de los Informes puede verse mermada si se admite que el DP da cuenta del resultado de su actuación y no, como de hecho sucede, de la actuación de la Administración pública y del Gobierno que la dirige. El hecho de que la presentación del Informe pueda convertirse en una forma de "orientar»-indirizzo- al DP, bien desde la mayoría gubernamental, bien desde los grupos de la oposición, resulta a todas luces criticable, toda vez que dicha presentación debe servir para impulsar la función de control pero no para que el DP sea objeto de la misma. Es indudable que el Parlamento goza de un cierto margen para pronunciarse sobre la actividad desplegada por su comisionado $^{17}$, pero también lo es que dicho margen no puede ser tan amplio que pueda repercutir, de cara al futuro, en la autonomía del DP a la hora de abordar la resolución de ciertos asuntos.

17 Véanse, en este sentido, las comparecencias del Consejero de Salud ante la Comisión de Salud y Consumo del Parlamento de Andalucía para pronunciarse sobre las propuestas formuladas en materia de sanidad por el Defensor del Pueblo Andaluz en sus Informes de 1993 y 1995. (Diarios de Sesiones del Parlamento de Andalucía n. ${ }^{\text {os }} 114$, de 25 de octubre de 1995 -pp. 3188 a 3193- y 91, de 30 de abril de 1997 -pp. 2328-2341-). 